\title{
Thai Khem Kaeng: An inadequate response by the Thai State to the impact of the 2008 economic
} crisis

\author{
John Walsh \\ Assistant Professor, School of Management, Shinawatra University \\ Bangkok 10400, Thailand \\ jcwalsh@siu.ac.th
}

\begin{abstract}
The economic crisis erupting from inadequate regulation of reckless banking practices in 2008 was correctly met by Keynesian-style stimulus packages in governments around the world. These measures were successful when they were sufficiently large, properly focused, and implemented promptly. Where these conditions were not met, as in the case of Thailand, the results were unimpressive and the problems not dealt with properly. However, the Thai version of the second part of the stimulus package, Thai Khem Kaeng, had in fact quite a different purpose and appears to have been intended to boost the popularity of the government at the cost of making unsustainable and uncosted deficits for the future. The lack of coherence at the economic planning centre of government and its questionable methods suggest that Thailand has continued the longstanding policy of making economic decisions for non-economic reasons.
\end{abstract}

Keywords: Thailand, stimulus package, competitiveness

\section{What is an Economic Stimulus Package?}

An economic stimulus package is a government policy aimed at providing rapid relief to a domestic economy through a mixture of monetary and fiscal policy issues. Policy issues commonly included in a stimulus package (SP) include increased government spending to provide jobs, boost demand for goods and services and provide enabling infrastructure from which the private sector can benefit, as well as tax cuts and related issues to stimulate private sector investment and consumption activities at the individual and organizational level. The purpose of an SP is to respond to an economic crisis that threatens the economy as a whole and which reduces confidence so that the private sector is unwilling or unable to act. The concept is based on the work of John Maynard Keynes, whose ideas demonstrated the means by which governments can fend off the worst aspects of economic crisis through expanding demand (Skidelsky, 2010). Keynes would also have thought in terms of the reduced interest rates that are part of monetary policy but, owing to the preceding economic conditions for a decade or more, interest rates have internationally been at extremely or historically low levels and so there has been little scope to act in this area.

In the wake of the 2008 crisis, led by the Prime Minister of the UK Gordon Brown, governments around the world created SPs of their own in the successful attempt to ward off the worst outcomes. Thailand, too, created an SP of its own, although it possessed somewhat different characteristics than those seen elsewhere. Those differences included the very long period of time that elapsed before many provisions were brought into place, the political decisions that determined the distribution of resources and the mismanagement of the economy as a whole that undermined the purpose and stated intention of the SP. This paper aims to explain the characteristics of the Thai economy and, hence, the type of SP necessary to assist it and then contrasts this need with the SP in fact provided. Subsequent sections indicate the progress that has been made over the last year.

\section{Political and Economic Context of Thailand}

The Thai economy relies to a significant extent upon exports and tourism. This makes the economy very susceptible to external environmental shocks: exports depend on international demand and may be undercut by rivals; tourism is also subject to the willingness of domestic and international customers to spend their money on tourist activities and the negative effects of natural disasters and epidemics (e.g. the 2004 tsunami, SARS, avian influenza) and political action (e.g. the 2008 seizure and occupation of Bangkok's international airports and, in 2010, massive levels of state violence against pro-democracy demonstrators). Exacerbating the reliance of the Thai economy on the external environment is the almost 
total absence of hydrocarbons in Thai territory and the need, therefore, to import oil and gas at international market prices. As is evident, the price of oil and gas has been mostly at elevated levels in recent years and, given the nature of scarce resources and ever-increasing demand, those high prices will be likely to continue into the foreseeable future. In addition, the Thai economy must also contend with the rise of new competitors such as China and Vietnam, able to provide rival goods at competitive prices. As standards of living have generally risen in Thailand, the ability of the country to compete in terms of the low prices of commodities or commodity-like objects has eroded. New forms of competitiveness are, consequently, required. The global economic crisis initiated by the banking crisis of 2008 has revealed the stark nature of the need for radical change in the Thai economy. The very model of development on which the economy has depended since the 1950s (which is a variant of what is termed here the East Asian Economic Model (EAEM)) is no longer appropriate to form the basis for future or even current economic progression. While the Thai Rak Thai administration of 2001-6 appreciated these issues and set in motion policies to convert the economy to work according to different dynamics, the disastrous military coup of 2006 has been followed by military rule and the subsequent installation by judicial means from 2008 of a military-approved regime which has proved to be brutal, corrupt and incompetent. This has been revealed starkly by the response to the ongoing economic crisis, which has been characterised by lack of focus, short-termism, political rather than economic criteria used for expenditure and the lack of a coherent vision for future development of the country.

This paper described the nature of the EAEM as it has been manifested in the case of Thailand, as a means of helping to understand how the economy needs to change in response to current and probably future changes in the global economy. It then goes on to describe and analyse the stimulus package and other measures taken by the Thai government as a means of combating the economic crisis and then provides a critique of that response.

\section{Methodology}

This paper adopts an analytical-critical approach to seeking to identify a specific research issue and to determine both the explanatory factors and that which is to be explained according to the logic of analytical induction. This method is validated by the work of previous contributors to the approach (Manning, 1982; Johnson, 1998). It aims to provide a causal explanation for the creation of a phenomenon (Thai Khem Kaeng) and its means of articulation. It would be preferable to construct a capacious database consisting of large numbers of responses to economic crisis relevant to the analysis in this case but such a task in impractical, given the urgency with which it is necessary to deal with the current case. Ongoing research seeks to locate the present case within a wider context.

\section{The East Asian Economic Model}

The East Asian Economic Model (EAEM) is based on import-substituting, export-promoting manufacturing with competitiveness based on low labour costs. Labour costs have been kept low, in general terms, by moving people from agriculture into industry, accepting inward flows of legal and illegal migrant workers and the use of the police and military to suppress workers' rights, freedom of association and freedom of speech. The rights of capitalist investors were placed decidedly ahead of those of workers (Studwell, 2007). The kinds of manufacturing industries involved have included garments and shoes, processed agricultural products and seafood, electronic components, automotive and semiconductors. In general terms, the technology for this kind of manufacturing is quite widely diffused around the world and the need for skilled workers limited. Commodity labour prices, in other words, have remained of the greatest importance. To support labour markets of this nature, it has been necessary for states to maintain educational systems that, for the working classes at least, promote rote learning, discipline (i.e. obedience) and the advancement of 'traditional cultural norms' such as deference to authority figures, willingness to accept injustice mutely and self-abnegation in the light of state development goals. The results of the education system are reinforced by additional aspects of the East Asian Development Model (EADM), which include limitations on democracy, censorship, self-censorship, promotion of national ideologies and, again, the need for obedience. The EADM routinely includes, therefore, a compliant pro-establishment media, patronage systems, neutered labour movements and a culture of antipathy towards politicians who might represent a genuine threat to the status quo. The EAEM relates to the economic basis of development of the country; the EADM includes the configuration of the political and cultural aspects that are also used to reinforce the economic base of development. 
All economic activities eventually become obsolete, of course, usually after having first passed through a period of decreasing relevance. This process is accelerated or intensified by the onset of an economic crisis such as that which began in 2008. Under conditions of competition, some firms will fail and others will flourish and grow in size and their structures become part of internationalized (and sometimes globalized) firm-firm networks and are embedded in international or global production networks (Chung, 2009). At such a point, it has been argued, the firms involved have effectively grown beyond the reach of the governments that helped to give them birth. Examples of such firms include Hyundai, LG and Samsung from Korea. However, the relationship between the Korean government and its economic actors was antagonistic for many years, particularly in the early parts of the Korean EAEM. Easing of tensions only occurred with overall growth of the national economy and the firms themselves found more resources to enact their future plans. Even so, the firms have still been enacting to some extent national development goals, albeit through incentives rather than obligation (Moon, 1994). As the leading firms increasingly recognise that their future growth lies as much in the Knowledge-Based Economy (KBE) as it does in manufacturing or services. The two have worked together to achieve high value-added production means and processes, with government providing infrastructure and highly-qualified labour while the private sector deals with entrepreneurial aspects, finance, marketing, distribution and so forth. Although the nature of the relationship has changed, therefore, its existence continues along different lines. This may not be possible in western countries, for example, where large and transnational firms have become much more decoupled from their original home states or host states (Hutton, 1996).

Clearly, therefore, the nature and indeed existence of the EAEM is not uncontested. There has been a tendency to see the nature of the developmental state as being, in simple terms, statist in nature: the state determines its various goals which it can force private sector agents to transact. In fact, as suggested above, the relationship between public and private sector in the developmental states of East Asia has neither been stable nor unproblematic. Thailand has broadly followed in the footsteps of Korea in that, lacking resources, the state has entrusted the private sector to carry out state developmental goals on behalf of the state which, in return, smoothes the way for firms to complete their own goals. There are other forms of relationship: in Taiwan, for example, developmental goals were entrusted to governmentlinked companies which, as their names suggest, are partly-owned and administered by the state and which can be expected to do what is required (Chu, 1994). The situation in mainland China at the beginning of the $\mathrm{C} 21^{\text {st }}$ has some similarities with the Taiwanese example in that State Owned Enterprises, in some cases corporatized or under some other organizational structure and ownership, are busily conducting economic activities which are congruent with national goals, particularly with respect to constructing infrastructure in the Mekong region. There are, in other words, significant variations within the different EAEMs and EADMs (e.g. Park, 2002). In some ways this reflects the different configurations of the superstructures of politics, culture and societal arrangements that sit atop the economic bases of the countries involved.

The spatial location of industrial development and related residential accommodation has also been significantly influenced by the EAEM. Commonly, certain areas of land are designated as being industrial estates, export processing zones, special economic zones or some similar terminology and these areas are provided with often subsidized public services such as electricity, water and transportation, while government-provided incentives are provided to encourage domestic and, especially, international investors to locate their economic activities there. Generally, these areas will be located with a view to low labour cost manufacturing rather than resource extraction activities. Consequently, there is a need to attract people to the area to take the jobs provided under the conditions available. In some cases, the local communities and provincial population centres will provide a sufficient labour force to meet demand but it is more likely that over-supply of labour will lead to a suppression of wages and the hiring of people from more remote regions where lower standards of living are normal. In some cases, ethnic minority people or international labour migrants are used to depress wages further and to undermine such labour rights as do exist. While this approach can provide some dynamic economic growth, it is also common for factories to be established aimed at conducting commercial or manufacturing activities which are only possible because of the conditions applying in the special zones in which they are located.

In any case, the concentration of workers means there is a need for accommodation, perhaps dormitories which can be more easily monitored, and the issues of social control that arise under such circumstances. Much factory work is considered to be gender-specific and, so, the accommodation must provide for a preponderance of either male or female workers. It is well-known that social issues may easily arise in these kinds of circumstances, while there may also be problems caused by sub-contractor companies and 
brokers. If transportation infrastructure improves, alongside personal living standards and hence the access to personal forms of transport, then the labour force may become more dispersed and seek to live in the more exciting urban communities. As is evident from similar situations around the world, the entrance of comparatively large numbers of newcomers into a settled community can be the cause of tension and possible conflict. This issue may be exacerbated when ethnic, regional or class issues are involved. Sensitive provision of public services and administration are required to handle the situation. As Kundu (2009) has observed, Thailand has in common with many Asian countries undergone processes by which the numbers of migrant including international migrant workers has increased considerably over recent decades and certain large urban centres are beginning to feel the strain of growth in terms of public service provision, pollution, crowding and o forth are concerned. From a positive perspective, it is possible for a country entering the EAEM or at an early stage of its working to seek to manage the spatial location of such industrial zones and to take action to ensure smooth provision of services and related matters. In terms of social issues, there is one specific consideration relating to changing gender relations. When groups of women are drawn to a remote area to work together in a factory setting and perhaps dormitory accommodation, they can in some cases be empowered to take a greater level of control over their own lives and personal relationships and this might prove to be problematic if they then return to home areas where less enlightened attitudes persist.

Finally, it is necessary to consider the issue of demographic change. Thailand has a population that is gradually ageing and the number of children being born per adult woman has been declining in conformity with well-known economic conventions. These changes are inimical to the smooth running of the EAEM, which requires a constant stream of new entrants into the labour market willing to work for low wages and to move across the country in response to new work opportunities. Since Thailand has a well-established seniority system in terms of terms and conditions, older workers tend to expect to be paid more purely as a result of their seniority and the presumption of greater experience and skill. As workers have tended to become older and, also, better paid, therefore, the ability of the country to maintain its current expression of the EAEM has declined to the same extent. The EAEM can be a powerful tool for economic change in a mostly poor country or in a country with a dual economy, one part of which has comparatively large numbers of poor people. However, it is not a tool that can be wielded without consideration for the externalities attendant upon it: instead, attention should be paid to the EAEM's impact upon geographic location of economic activities, its dynamic nature in changing the lives of those involved with it and its impact on social and gender relations, among other area. Above all, the EAEM is a dynamic and transitory force, which cannot be preserved indefinitely and nor should it be. It is clear from this analysis that it is the manufacturing and tourism sectors that bear the brunt of external economic downturns. Consequently, SP policies should be largely focused on protecting those sectors from the short-term downturns which are unlikely to last more than two or three quarters while enabling employees to be retained and preventing deskilling problems. Skilled workers remain at a shortage in the Kingdom as a whole and the problems of job-hopping and external migration remain genuine threats. In contrast with western countries, Thailand's experience with the 1997 crisis (in common with a number of other East Asian nations) meant that its banks have tended to be comparatively conservative in behaviour subsequently and have avoided the more exotic new financial instruments (Chalongphob and Jitsuchon, 2009). Most other Thai citizens were largely unaffected by the crisis directly. They would, nevertheless, benefit from those forms of enabling infrastructure which has general application across a developing economy, as for example in broadband internet provision (Qiang, 2010). The problem for the rightist Abhisit regime, though, is that its political support has rested almost entirely on the urban residents of Bangkok (migrant workers are not permitted to register to vote there), among professionals and civil servants and in the middle and upper classes. Further, the working classes have mounted numerous large-scale demonstrations against the legitimacy of the Abhisit regime and demanding proper democracy for the country and accountability from opaque but extremely powerful institutions it is generally considered illegal even to name in such a context.

\section{The Response to the Crisis: Thai Khem Kaeng}

The Thai government took action to provide economic stimulus, in line with the zeitgeist, not wishing to be thought of as being out of step with international sentiment. The stimulus package was launched under the slogan Thai Khem Kaeng ('Stronger Thailand'). It consisted, initially, of a proposed and subsequently implemented budget that provided for funds in specific areas. These included plans to extend free public sector education places, create as many as 10,000 new hospital beds in the public sector and develop a number of small and medium size infrastructure projects between 2010-2 (on the basis that large-scale 
infrastructure projects are being financed at least in part by the Asian Development Bank and other international partners). The first package, known as SP1, was aimed primarily at alleviating the misery of the poor through short-term tax breaks, subsidies for public utilities and services for low income households, as well as one-time cash handouts for low-income workers (Chantanusornsiri, 2009). SP1 had a limited impact because of its small scale and lack of proper focus and because of the lack of effective legal monitoring of the social security system and employment (Chandoevwit, 2010). For example, a recent report by the ILO reported that some $25 \%$ of workers in the manufacturing sector received less than the legally-mandated minimum wage (ILO, 2010).The second part of the package has become known as SP2 or Thai Khem Kaeng and involves committing some 1.43 trillion baht for numerous loosely-defined infrastructure projects across the range of the country and its various industries (progress in these projects is detailed in the table below).

Table 1: Progress of Projects under SP2 (Thai Khem Kaeng)

\begin{tabular}{llll}
\hline & NO OF PROJECTS & VALUE (MN BAHT) & \%AGE \\
\hline Approved & 42,258 & $349,960.44$ & 100 \\
Allotment & 38,922 & $320,760.88$ & 91.6 \\
Signed contract & 35,985 & $292,028.20$ & 83.4 \\
Disbursed & 34,231 & $234,400.87$ & 66.9 \\
Completed & 1,940 & $33,078.79$ & 9.4 \\
\hline
\end{tabular}

\section{Source: Government Website: http://www.tkk2555.com/online/}

To meet these promises, if indeed they are to be met, the government plans to run deficit budgets for the next few years as public debt is anticipated to increase from $40 \%$ of GDP at the end of 2009 to as high as $60 \%$ of GDP at its highest point. Subsequent policies have been characterized as 'populist' in terms of offering free services to various sectors of society with no apparent attempt to explain how these expensive redistributions will be paid for, if at all. Even the strongly pro-establishment official Thai media (most of the unofficial Thai media has been closed down by the increasingly autocratic Abhisit regime) has shown signs of understanding that these policies differ from those of Thai Rak Thai, which were roundly condemned as 'vote-buying,' only in that Thai Rak Thai was working with a vision for the economy on the medium and long term while the Abhisit regime is simply clinging to power by trying to bribe the voters they think might one day vote for them. In any case, it is clear that government projections for the recovery of economic growth depend on the return of export markets to their previous levels. It is by no means certain that these markets will swiftly or persistently return to pre-crisis levels, though, since many European nations have ignored the lessons provided by Keynes of avoiding economic recessions by expanding the public sector to become the principal engine of growth until such time as the private sector is able to resume this role. Instead, these states are precipitately rushing to reduce their deficits and hope, without much evidence to justify such a hope, that they will be able to export their way back into positive growth. This has an impact around the world, of course, since international trade links many states to many: in a globalized world, decline in imports in one country or region tends to spread around the world and, when recession has already weakened international confidence internationally, the system remains fragile. To understand the nature of the Thai response to the crisis, it is helpful to consider the component of the creative industries, which is indicative of the nature of the two stimulus packages (see table below).

Table 2: Creative Economy funding, 2010-2 (figures in millions of baht).

\begin{tabular}{|c|c|c|c|c|c|}
\hline MINISTRY/AGENCY & PROJECTS & $\begin{array}{l}2010 \\
\text { BUDGET }\end{array}$ & $\begin{array}{l}2011 \\
\text { BUDGET }\end{array}$ & $\begin{array}{l}2012 \\
\text { BUDGET }\end{array}$ & TOTAL \\
\hline ICT Ministry & 1 & 200.0 & 0 & 0 & 200.0 \\
\hline $\begin{array}{l}\text { Natural Resources and } \\
\text { Environment }\end{array}$ & 3 & 301.0 & 175.0 & 174.0 & 650.0 \\
\hline PM's Office & 6 & $2,654.5$ & $2,805.3$ & $2,805.3$ & $8,265.0$ \\
\hline Industry Ministry & 22 & $1,452.7$ & $3,655.4$ & $2,265.1$ & $7,373.1$ \\
\hline Public Health Ministry & 2 & 10.0 & 7.0 & 7.0 & 24.0 \\
\hline $\begin{array}{l}\text { Science and Technology } \\
\text { Ministry }\end{array}$ & 8 & 930.0 & $1,031.0$ & $1,021.0$ & $2,982.0$ \\
\hline Culture Ministry & 3 & 250.0 & 77.0 & 313.0 & 640.0 \\
\hline Total & 45 & $5,798.2$ & $7,750.6$ & $6,585.4$ & $20,134.1$ \\
\hline
\end{tabular}


First of all, it is notable that a large proportion of the budget concerned has been allocated to the Prime Minister's Office, which makes scrutiny of disbursement and selection particularly difficult. Second, the funding was not put into place until 2010 at the earliest, despite the realization in 2008 that urgent action was required. Third, the composition of the funding leaves some decisions open to question. This is in part because of the perceived dimension of allocating projects to different areas depending on the control of ministries within the ruling coalition. Hence, only three projects were awarded to the Culture Ministry while 22 were allotted to the Industry Ministry. A government spokesperson claimed that some proposals had been rejected because they had simply added the word 'creative' to the proposal forms and provided examples of the successful projects funded under the Prime Minister's Office, under the Office of Knowledge Management and Development (who provided the abovementioned spokesperson): “... the Creative City; the OKMD Creative Awards; the executive creative economic training programme; the Creative Mobile, which provides knowledge and training for people upcountry through road shows; and website development to publicize information. The Creative City initiative, running from November 2009 to March 2010, includes Creative Shops in Bangkok, a Creative Music Festival where a variety of concerts, some featuring "underground" artists will be staged, and Creative Studio, which provides space for anyone wishing to showcase their achievements. The Bangkok Food Festival would also be held to promote the capital as not only a city of fun but also a city of food diversity (Theparat, 2009)." It is clear from this that the creative industries are defined as including international interests and without any specific element of 'Thainess' - although this concept has been used in other aspects of contemporary government policy (Apivantanaporn and Walsh, 2010). It is also clear that this approach appears dominated not just by urban-centred policies but by a vision of consumerist globalisation that is generally rejected in ideological terms by the Abhisit regime and its supporters. Indeed, these policies might well have derived from the previous, much derided Thai Rak Thai administration. This form of capitalism is in many ways a logical response to the crisis of capitalism with which Thailand as part of the modern world has been faced but admitting it would be more honest.

\section{Critique of the Thai Response}

As the World Bank has indicated, economic recovery in Thailand has depended almost entirely on the recovery of exporting as international export markets have (perhaps only temporarily) returned to their previous levels prior to the crisis (World Bank, 2010). This is problematic and renders much of the rest of the programme vulnerable to the charge that it is either just window-dressing or the reassignment of existing (or aspirational) policies under a different name for the government's marketing purposes.

The Thai Khem Kaeng campaign has been mixed in terms of success. While the use of an economic stimulus package was clearly correct in the prevailing conditions, the way in which it has been structured and administered has been problematic. The principal areas of concern are:

1. Lack of transparency in terms of prioritizing specific projects. It is widely thought that party political considerations have been influential in determining which of the competing projects receive funding. This has been because of the perceived need for the Democrat party to reward its coalition members with revenue-making opportunities;

2. The tardiness with which funds have actually been disbursed. It has become something of a tradition for right-wing Thai governments to try to conserve parts of its budget, perhaps to allow for contingencies or to permit some kind of discretionary spending;

3. the focus of much of the spending: while there was clearly a need for some relief assistance to the poor, too many projects aimed to be purely redistributive in nature without any meaningful anticipation of leading to economic growth overall;

4. The lack of an overall vision for the future direction of the economy. What vision has been revealed seems to be based on the idea that short-term survival will be sufficient until such time as the rest of the world is ready to begin importing once again. At the time of writing, it appears that the excessive deficit-cutting in Europe is putting the economic revival sparked by the early Brown-Obama leadership is in danger of being squandered;

5. The lack of co-ordination between different aspects of economic policy, leading to the underdevelopment (or even contradiction between) the different elements of government action. Free 
education is to be extended, for example, for students of government sector schools yet there is no mechanism that links demand for labour with its supply. Indeed, many government agencies not only compete with each other for scarce resources but even replicate each other's activities.

In addition to these issues, what is perhaps just as important is the way in which party political interests have contradicted stated economic goals. For example, competitiveness in exporting has been significantly undermined by the continual rise of the value of the baht resulting from continued inward flows of capital, the desire for entry into the KBE has been ruined by the incredibly severe restriction of free speech and civil liberties by the Abhisit regime (which has banned more than one hundred thousand websites, closed dozens of community radio stations, arrested numerous people for the supposed crime of lèse majesté and held the threat of emergency rule over much of the country), while the resurrection of the EAEM by inviting more inwards investment has been hampered by the incompetent handling of the pollution caused by certain installations in the Map Tha Put Industrial Estate. Irrespective of any virtues attached to the Thai Khem Kaeng programme, its values and purposes have been almost totally obscured by contradictory and often short-term, party-political policies and initiative announced by members of the Abhisit regime. This has seriously and needlessly undermined the possible recovery of the Thai economy, which has of course fallen most harshly on the poor and the vulnerable.

\section{Conclusion}

One of the often overlooked benefits of the globalized world is that governments whose economies are irrevocably opened to the rest of the world can usually do only short-term damage to their countries. Markets, fairly or unfairly, will seek to take advantage of inane policies and self-correcting mechanisms in the forms of banks, diplomatic pressure and social unrest will tend to bring about corrections sooner or later. So, at least, must be the hope of Thai people and investors in that country, as they see creativity stifled by censorship, competitiveness unhinged by subsidies and exports strangled by the uncontrolled rise of the baht. These factors work against the SP introduced to fight the impacts of the 2008 crisis and which was divided into two parts: the first was unmemorable and featured a few poorly thought out transfers and benefits seemingly carefully aimed at people who did not need them because of the crisis (although any were generally in need of assistance); the second, Thai Khem Kaeng, shows the division in the heart of the Thai state. On the one hand, generally well-educated technocrats up to date with contemporary thinking and discourse concerning social and economic development and able, therefore, to put together the rubric and justification for policies with, on the other hand, unscrupulous and conniving politicians who will subvert those policies for purposes of their own. Yet these dealings remain essentially peripheral since the Thai economy is built on a much larger scale, that of the EAEM and it is management of this and its transition to a new state that should be the principal economic issue of the day.

In terms of recommendations, it is evident that the main point is for the Thai government to seek to return to evidence-based policy and to cease making important economic decisions for narrow partisan purposes. The future of the Thai economy is much more important than the destiny of a gang of transient politicians and their connections. Policies should redirect resources towards meaningful and rapid infrastructure development and to begin to phase out the numerous subsidies and mostly fruitless handouts currently available. Planning beyond the next political or electoral cycle is also needed and, to provide the necessary incentives to adopt this, genuine democracy should be restored, together with the freedom of association and freedom of speech necessary for individuals and organizations to begin to participate properly in the KBE.

\section{References}

Apivantanaporn, T. \& Walsh, J. (2010): Innovative drivers for new business creation. Paper presented at the ICBER (Kuala Lumpur).

Chandoevwit, W. (2010): The impact of the global financial crisis and policy responses in Thailand. TDRI Quarterly Review, 25(1), 12-24.

Chantanusornsiri, W. (2009): From strength to strength. Bangkok Post 2009 Year-End Economic Review, 12

Chu, Y-H. (1994): The realignment of business-government relations and regime transition in Taiwan. In MacIntyre, A. Ed., Business and Government in Industrialising Asia. Ithaca, New York: Cornell University Press, 113-41. 
Chung, H. W.C. (2009): Drivers of globalization: An evolutionary perspective on firm-state relations in the Asian newly industrialized economies. Papers in Evolutionary Economic Geography, \#9.20 (University of Utrecht), available at: http://econ.geo.uu.nl/peeg/peeg.html.

Gill, I. \& Kharas, H. (2007): An East Asian renaissance: Ideas for economic growth. New York: World Bank.

Hutton, W. (1996): The state we're in. Revised edition. London: Vintage.

International Labour Organization. (2010): Global wage report 2010/11: Wage policies in times of crisis. Geneva: ILO.

Johnson, P. (1998). Analytic Induction. In Symon G \& Cassell C. eds., Qualitative Methods and Analysis in Organizational Research. Sage, London.

Kundu, A. (2009): Urbanization and migration: An analysis of trends, patterns and policies in Asia. Human Development Research Paper, 2009/16 (December) United Nations Development Project. Available at: http://mpra.ub.uni-muenchen.de/19197/.

Manning, P.K. (1982): Analytical induction. In Smith, R.B. and Manning, P.K., Handbook of social science methods: Qualitative methods. Cambridge, MA: Ballinger.

Moon, C-I. (1994): Changing patterns of business-government relations in South Korea. In MacIntyre, ed., op.cit. 142-66.

Park, J.H. (2002): The East Asian model of economic development and developing countries, Journal of Developing Societies, 18(4), 330-53.

Qiang, C. Z.-W. (2010): Broadband infrastructure investment in stimulus packages: Relevance for developing countries. Info, 12(2), 41-56.

Skidelsky, R. (2010): Keynes: The return of the master. London: Penguin.

Studwell, J. (2007): Asian godfathers: Money and power in Hong Kong and South-East Asia. London: Profile Books.

Sussangkarn, C. \& Jitsuchon, S. (2009): The sub-prime crisis and Thailand's growth rebalancing. TDRI Quarterly Review, 24(2), 3-9.

Theparat, C. (2009): Firms seeking state funds must match words with deeds. Bangkok Post Year-End Economic Review, 27.

World Bank. (2010): Thai economic recovery still driven by export growth, World Bank says. Available at: http://go.worldbank.org/1EV62T8NR0. 